\title{
ANALISIS PENGGUNAAN LIGHT FISHING DAN UNDERWATER LIGHT FISHING PADA BAGAN PERAHU DI PERAIRAN BOTANG LOMAN HALMAHERA SELATAN
}

\author{
Analysis of Light Fishing and Underwater Light Fishing Utilization on Liftnet Fishing at Batang \\ Loman Water, South Halmahera
}

Oleh:

Marwan Adam ${ }^{1 *}$, Sulaeman Martasuganda ${ }^{2}$, Eko Sri Wiyono ${ }^{2}$

${ }^{1}$ Mahasiswa Pascasarjana Departemen PSP FPIK IPB

${ }^{2}$ Staf Pengajar Jurusan Teknologi Perikanan Laut Departemen PSP FPIK IPB

*Korespondensi: marwanalfariji@gmail.com

\begin{abstract}
ABSTRAK
Bagan perahu adalah alat penangkapan ikan yang digolongkan ke dalam jaring angkat (lift net). Nelayan Desa Bajo menggunakan bagan perahu untuk menangkapan ikan pelagis kecil. Bagan perahu adalah salah satu alat tangkap yang dioperasikan pada malam hari dengan menggunakan cahaya. Nelayan Desa Bajo pada saat pengoperasian masih berdasarkan pengetahuan dan kebiasaan nelayan. Penelitian ini untuk mengetahui efektivitas dan efisiensi operasi penangkapan ikan maka diperlukan metode lain dalam penentuan daerah penangkapan ikan dengan menggunakan fish finder dan underwater light fishing, guna pengoperasian bagan perahu dapat berjalan dengan baik. Menganalisis hasil tangkapan berdasarkan bulan dan perlakuan. Hasil tangkapan selama penelitian menunjukkan bahwa total hasil tangkapan baik pada bulan gelap maupun bulan terang, jenis ikan layang dan ikan teri lebih mendominasi berada pada perlakuan kedua, sedangkan komposisi hasil tangkapan setelah tengah malam lebih banyak dibandingkan sebelum tengah malam, hal ini didasarkan dengan penelitian Sudirman et al. (2003) pada penelitiannya tentang adaptasi retina mata ikan layang (Decapterus ruselli) bahwa ikan yang dominan tertangkap adalah ikan layang karena teradaptasi sempurna oleh cahaya. Hasil penelitian dapat disimpulkan bahwa: Hasil tangkapan oleh enam jenis ikan yang dominan tertangkap adalah, spesies layang (Decapterus russelli) mendominasi selama penelitian. Fase bulan yang terbaik adalah pada saat bulan gelap. Hasil tangkapan pada perlakuan kedua menggunakan lampu normal, fish finder dan underwater light fishing mendominasi selama penelitian.
\end{abstract}

Kata kunci: bagan perahu, light fishing, fish finder dan underwater light fishing.

\begin{abstract}
Boat Lift Net is a fishing gear that classified into lift nets. Basically, fishermen of Bajo Village use boat lift nets to catch small pelagic fish. Boat Lift Net is one of fishing tackles operated at night using light. During its operation, the fishermen of Bajo Village are still based on their knowledge and habits. Therefore, to know the effectiveness and efficiency of fishing operations, another method is necessary in determining the fishing ground by using fishfinder and underwater light fishing, so that the operation of boat lift net can run well. The objectives of this study are analyzing the catch based on and lunar phase. The catch during the study shows that the total catch in either dark moon or full moon is more dominated by Decapterus Russelli at the second treatment. While the catch is obtained more at midnight than before midnight. This is based on the study conducted by Sudirman et al (2003) in his research on the adaptation of Decapterus Russelli retina indicating that the catch is more dominated by Decapterus Russelli as they are perfectly adapted by light. The conclusions taken
\end{abstract}


in this research are: The catch of the six species of fish is dominated by the species of floating fish (Decapterus russelli). The best moon phase is in the dark months. The catch in the second treatment using normal light, fish finder and underwater light fishing dominated during the study.

Keywords: boat lift net, light fishing, fish finder, underwater light fishing.

\section{PENDAHULUAN}

Bagan adalah alat penangkapan ikan yang digolongkan ke dalam kelompok jaring angkat (lift net). Jenis-jenis bagan yang sering digunakan oleh nelayan di perairan Indonesia adalah bagan rambo, bagan perahu, bagan apung, bagan tancap dan bagan rakit. Jenis alat tangkap bagan yang digunakan oleh nelayan Desa Bajo yang dioperasikan di perairan Botang Loman adalah bagan perahu. Bagan perahu merupakan salah satu jenis alat tangkap ikan yang dioperasikan pada malam hari dengan bantuan cahaya/light fishing, hal ini ditegaskan oleh penelitian menurut Ayodhyoa (1981) mengelompokan bagan ke dalam light fishing karena menggunakan lampu sebagai alat bantu untuk merangsang atau menarik ikan menuju catchable area. Target utama penangkapan ikan dari bagan perahu nelayan Desa Bajo adalah jenis-jenis ikan pelagis kecil.

Bagan perahu memiliki kesulitan dalam menentukan daerah penangkapan ikan sehingga dapat mengakibatkan hasil tangkapan yang tidak pasti. Penentuan daerah penangkapan ikan masih berdasarkan metode pendugaan (trial error). Olehnya itu, diperlukan adanya metode lain untuk memastikan daerah penangkapan ikan agar dapat mengetahui gerombolan ikan dengan menggunakan alat fish finder. Fish finder merupakan alat bantu dengan memanfaatkan "echo" dalam pendeteksian ikan. Penggunaan fish finder perlu diperkenalkan agar dalam pencarian atau pendeteksian gerombolan ikan bersifat lebih "pasti" sehingga diharapkan terciptanya efektivitas dan efisiensi dalam proses penangkapan. Nelayan Desa Bajo mengoperasikan bagan ketika bulan gelap, dan sebaliknya pada bulan terang terpaksa tidak melaut, hal ini dikarenakan rendahnya hasil tangkapan di bulan terang, karena pada bulan terang, cahaya yang jatuh ke perairan menyebar merata, akibatnya ikan tersebar dan berenang ke perairan lebih dalam, sehingga penangkapan tidak efektif. Menurut Lee (2010), dari hasil penelitiannya terdapat perbedaan nyata antara hari bulan terhadap bobot hasil tangkapan bagan tancap.

Hasil tangkapan sangat dipengaruhi oleh faktor perubahan hari bulan, waktu penangkapan dan interaksi keduanya, namun untuk ikan demersal hanya dipengaruhi oleh waktu penangkapan, selain penentuan daerah penangkapan ikan, faktor lain yang penting dalam perikanan lampu adalah memastikan gerombolan ikan berada dalam areal penangkapan ikan. Martasuganda (2014), mengatakan bahwa gerombolan ikan hanya akan tertarik pada cahaya apabila intensitas cahaya dipasang di atas permukaan air bisa menjangkau gerombolan ikan. Kemudian terbatasnya kemampuan intensitas cahaya untuk menjangkau gerombolan ikan bergantung pada besarnya intensitas cahaya di dalam perairan, hal ini terjadi karena beberapa ikan memiliki swimming layer yang berbeda-beda.

Penggunaan light fishing di Desa Bajo perairan Botang Loman bisa berjalan efektif yaitu dengan menggunakan fish finder, di sisi lain pada kondisi berbeda dibutuhkan underwater light fishing untuk menarik gerombolan ikan ke coverage area atau dalam jangkauan intensitas cahaya dari light fishing yang dipasang pada permukaan perairan, berdasarkan hal tersebut sehingga penelitian ini sangat perlu dilakukan sebagai upaya untuk mengembangkan pengoperasian perikanan bagan perahu menjadi lebih efektif dan efisien di perairan Botang Loman Halmahera Selatan. Sedangkan tujuan dari penelitian ini adalah, menganalisis hasil tangkapan berdasarkan bulan perlakuan dan waktu. 


\section{METODOLOGI PENELITIAN}

Penelitian dilakukan pada bulan September sampai dengan Oktober Tahun 2016, berdasarkan dua fase bulan yang berbeda. Posisi fishing base berada pada Garis Lintang $0^{\circ} 36^{\prime} 29,69^{\prime \prime} \mathrm{LS}$ dan Garis Bujur $127^{\circ} 20^{\prime} 30,52^{\prime \prime B T}$ terdapat 12 trip. Pengoperasian ini dibagi atas 6 trip bulan gelap dan 6 trip bulan terang sebanyak 24 kali setting. Lokasi di perairan Botang Loman Kabupaten Halmahera Selatan. (Gambar 1).

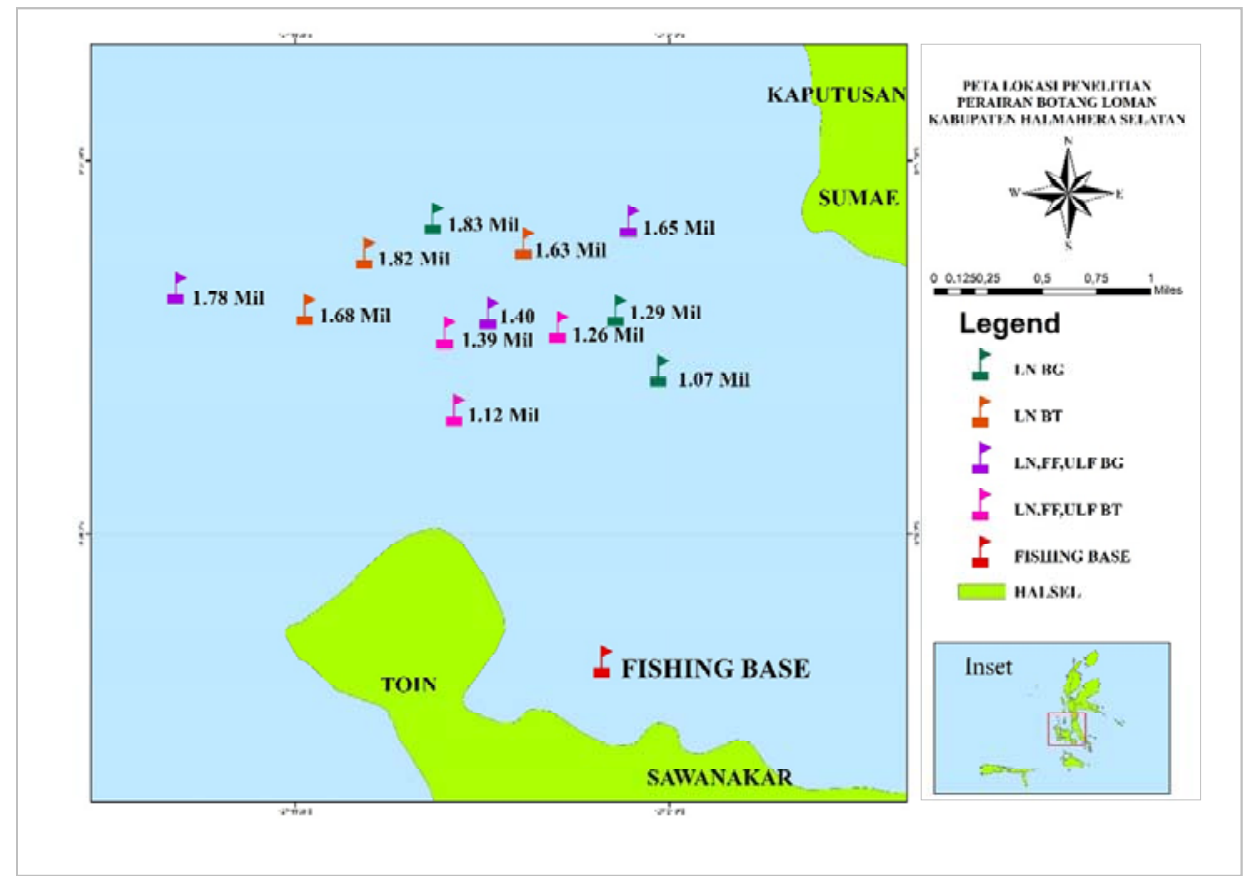

Gambar 1 Peta lokasi penelitian

Rancangan yang digunakan adalah uji ANOVA melalui SPSS dan uji Tukey melalui MINITAB. Teknik ini biasa digunakan pada kluster kelompok (group) dalam jumlah yang sama, dimana setiap kelompok diberikan beberapa perlakuan.

Bagan perahu yang digunakan dalam penelitian ini adalah bagan perahu nelayan milik Rusli Naser (ukuran bingkai $22 \mathrm{~m}$ x $21 \mathrm{~m}$ ), lampu philips 14 unit ditambah satu unit lampu fokus. Satu unit bagan perahu terdiri atas beberapa komponen utama yang saling terkait satu sama lain. Komponen tersebut adalah: perahu, rangka, waring, bingkai jaring, roller, generator set (genset), lampu philips lampu fokus dan rumah bagan. Kontruksi bagan perahu yang dimiliki nelayan Desa Bajo Kabupaten Halmahera Selatan, dilihat dari tampak samping maupun tampak depan sesuai dengan penempatan komponennya masing-masing. Bagan perahu dapat mengoperasikan di perairan Botang Loman Kabupaten Halmahera Selatan (Gambar 2). 


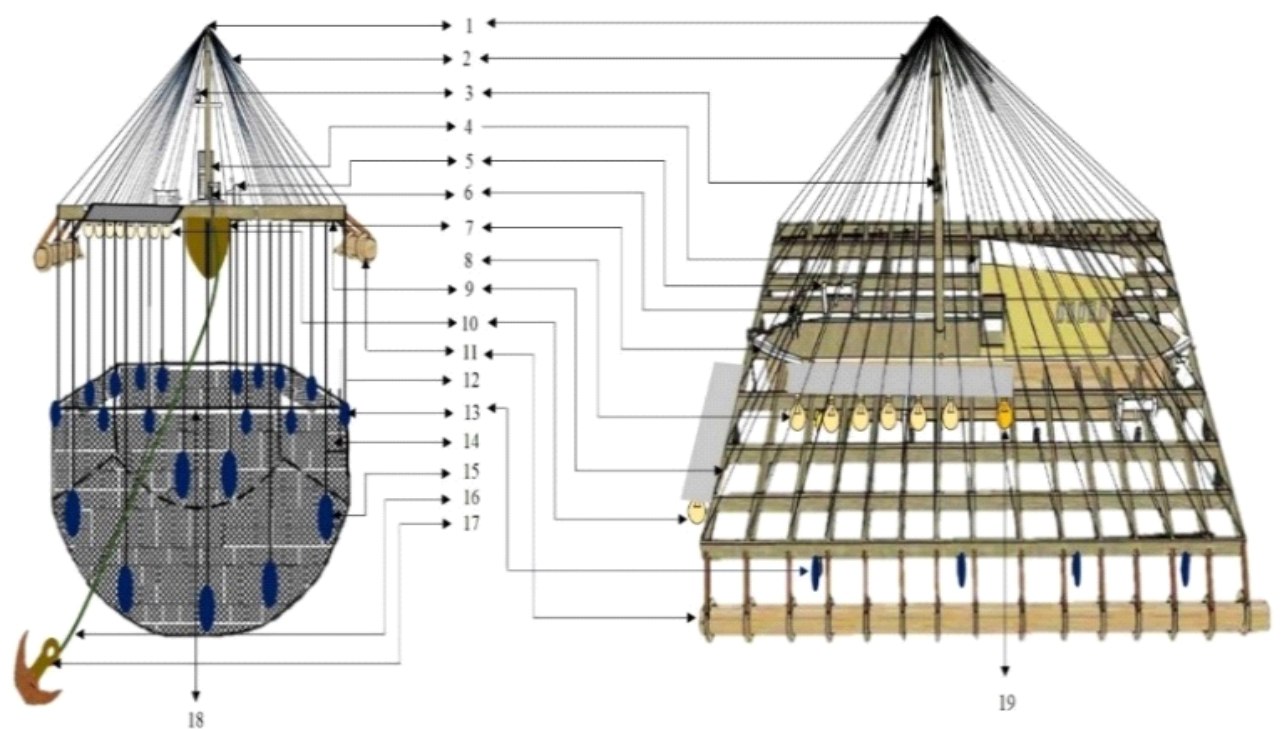

Keterangan:

1. Tiang utama (Kayu Meranti 13 meter)

2. Kawat Baja ( $d=0.8 \mathrm{~cm} 60$ buah)

3. Lampu tiang (mercuri 250 watt, warna putih)

4. Rumah Bagan (LBD $=3 \mathrm{~m}, 2 \mathrm{~m}, 2.50 \mathrm{~m}$ )

5. Roller jaring (kayu bulat ; $2 \mathrm{~m}$ )

6. Roller jangkar (kayu bulat;1.5 m)

7. Perahu bagan (LBD = $22 \mathrm{~m} 21 \mathrm{~m}$ )

8. Lampu samping (philips 6 buah)

9. Anjang-anjang (Kayu meranti, panjang $22 \mathrm{~m}$ lebar 21 $\mathrm{m})$
10. Lampu depan philips (8 unit)

11. Cadik bagan (Bambu panjang $22 \mathrm{~m}$ lebar 21m)

12. Tali penurunan bingkai jaring $(40 \mathrm{~m})$

13. Pemberat bingkai jaring (5 kg 16 buah)

14. Waring (PE)

15. Pemberat jaring dan penahan arus ( $15 \mathrm{~kg}, 8$ buah)

16. Tali jangkar

17. Jangkar

18. Bingkai jaring (panjang $22 \mathrm{~m}$, lebar $21 \mathrm{~m}$

19. Lampu fokus (pijar 1 unit warna kuning 65 watt)

Gambar 2 Desain bagan perahu yang digunakan selama penelitian

Penelitian ini menggunakan rancangan faktorial. Teknik ini biasa digunakan pada kluster kelompok (group) dalam jumlah yang sama, dimana setiap kelompok diberikan beberapa perlakuan. Penelitian ini terdiri dari 2 perlakuan yaitu (a1) lampu normal (a2) lampu normal, fish finder dan underwater light fishing dengan masing-masing dilakukan 3 trip, (t1) Trip pertama (t2) Trip kedua dan (t3) Trip ketiga. Fase bulan yaitu $(\beta 1)$ bulan gelap $(\beta 2)$ bulan terang, sedangkan dalam satu trip terdiri dari dua kali setting yaitu $(\gamma 1)$ sebelum tengah malam $(\gamma 2)$ setelah tengah malam Yijk adalah hasil tangkapan(Tabel 1).

Metode yang kedua yaitu menganalisis hasil tangkapan berdasarkan bulan, perlakuan dan waktu penangkapan dengan uji ANOVA melalui SPSS

Model yang digunakan sebagai berikut:

Yijkl $\quad=\mu+\alpha i+\beta j+\gamma_{-} k+\varepsilon i j k l$

dengan:

Yijkl = Hasil tangkapan pada lampu ke-i, bulan ke-j, waktu ke-k, ulangan ke-l

$\mu=$ Rataan umum

$\alpha \mathrm{i}=$ Pengaruh lampu ke-i

$\beta \mathrm{j} \quad=$ Pengaruh bulan ke-j

$\gamma_{-} \mathrm{k}=$ Pengaruh waktu ke-k

eijkl = Galat 
Tabel 1 Model desain penelitian

\begin{tabular}{|c|c|c|c|c|c|}
\hline \multirow{2}{*}{$\begin{array}{c}\text { Perlakuan } \\
\text { (a) }\end{array}$} & \multirow{2}{*}{$\begin{array}{c}\text { Tri } \\
\mathrm{p}\end{array}$} & \multirow{2}{*}{ Waktu $(\gamma)$} & \multicolumn{2}{|c|}{ Bulan $(\beta)$} & \multirow{11}{*}{$\begin{array}{l}\text { a } 1 \text { = Lampu normal } \\
\text { a } 2 \text { = Lampu normal dan fish finder } \\
\text { Underwater Light Fishing } \\
\text { t1= Trip pertama } \\
\text { t2= Trip kedua } \\
\text { t3 = Trip ketiga } \\
\gamma 1=\text { Waktu sebelum tengah malam } \\
\gamma 2=\text { Waktu setelah tengah malam } \\
\beta 1=\text { Bulan Gelap } \\
\beta 2=\text { Bulan Terang }\end{array}$} \\
\hline & & & $\beta 1$ & $\beta 2$ & \\
\hline \multirow{6}{*}{ a 1} & $\mathrm{t} 1$ & $\gamma 1$ & Y111 & Y111 & \\
\hline & & $\gamma^{2}$ & Y112 & Y112 & \\
\hline & $\mathrm{t} 2$ & $\gamma 1$ & Y211 & Y211 & \\
\hline & & $\gamma^{2}$ & Y212 & Y212 & \\
\hline & $\mathrm{t} 3$ & $\gamma 1$ & Y311 & Y311 & \\
\hline & & $\gamma^{2}$ & Y312 & Y312 & \\
\hline \multirow{6}{*}{ a 2} & $\mathrm{t} 1$ & $\gamma 1$ & Y111 & Y111 & \\
\hline & & $\gamma^{2}$ & Y112 & Y112 & \\
\hline & $\mathrm{t} 2$ & $\gamma 1$ & Y211 & Y211 & \\
\hline & & $\gamma^{2}$ & Y212 & Y212 & \\
\hline & $\mathrm{t} 3$ & $\gamma 1$ & Y311 & Y311 & \\
\hline & & $\gamma^{2}$ & Y312 & Y312 & \\
\hline
\end{tabular}

\section{HASIL DAN PEMBAHASAN}

Pengoperasian satu unit bagan perahu membutuhkan minimal 6 orang anak buah kapal (ABK) yang dipimpin oleh seorang juragan laut. Juragan laut memimpin dan bertanggung jawab penuh terhadap seluruh operasi penagkapan ikan yang dilakukan. Tugas masing-masing ABK pada saat operasi dibagi atas, satu orang mengatur pencahayaan lampu, satu orang mengatur tali jangkar pada saat haulling, dan empat orang lainnya bertugas memutar roller dan menggiring ikan pada salah satu sisi bagan yang berfungsi sebagai kantong. (Gambar 3).

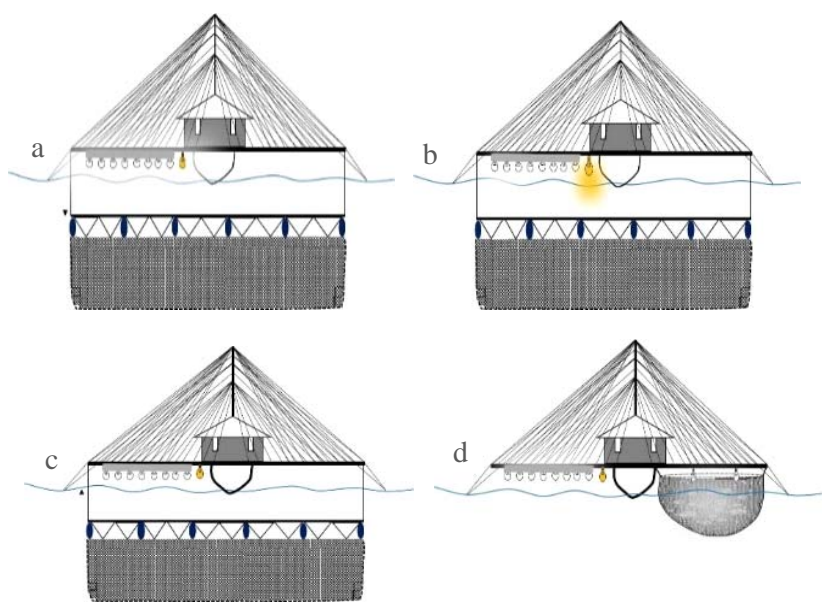

Keterangan :

(a) Setting, (b) Pemandaman lampu satu persatu, (c) Hauling, (d) Handling

Gambar 3 Ilustrasi pengoperasian bagan perahu

Proses penangkapan dimulai dengan penentuan fishing ground berdasarkan pengalaman oleh nelayan setempat. Bagan dijalankan dengan mesin penggerak 30 PK, dan didorong dengan kapal kecil ke fishing ground. Jarak dari fishing base ke fishing ground sudah ditentukan melalui Global Position System (GPS). Lama waktu yang dibutuhkan ke fishing ground sekitar 2 jam, diawali dengan penurunan jangkar pada fishing ground dilakukan setelah pengecekan dasar perairan. Dasar perairan sebaiknya berlumpur agar terlindung dari arus. Menurut Safrudin (2013) menyebutkan setiap jenis ikan membutuhkan kisaran kondisi perairan yang optimum untuk kehidupannya. 
Penyalaan lampu dimulai pada saat matahari terbenam (pukul 18. 00 WIT). Dengan waktu 3 sampai 4 jam setelah lampu dinyalakan akan dilakukan pemadaman lampu dimulai dari lampu depan samping kanan bagan secara bertahap dan pada akhirnya hanya lampu fokus yang menyala dan diredupkan berlahan selama 10-15 menit sehingga ikan semakin mendekat ke tengah bagan. Penarikan jaring dilakukan setelah juragan mengamati secara visual kawanan ikan yang terdapat di bawah rangka bagan. Kemudian akan dilakukan pemasangan jaring di setiap sudut bagan pada bingkai yang dilengkapi dengan pemberat, empat orang yang bertugas sebagai pemutar roller akan diturunkan dengan cepat agar ikan pada catchable area tidak meloloskan diri.

Jaring yang berada dalam air berkisar antara 25-30 m, waktu yang dibutuhkan untuk menarik jaring sampai ke permukaan umumnya lama penarikan jaring 10 menit, selanjutnya ikan yang sudah berada dalam jaring akan digiring ke sisi kiri rangka bagian belakang dan lampu akan dinyalakan kembali untuk melihat spesies apa saja yang tertangkap, ikan dapat diangkat dengan serok ke atas perahu agar bisa dilakukan penyortiran, kecuali ikan teri. Karena jenis ikan ini akan diambil dalam keadaan hidup dengan menggunakan ember ukuran berat $19 \mathrm{~kg}$, dalam satu ember harga Rp 100.000 yang di ambil oleh kapal pole and line untuk menggunakan umpan pemancingan ikan cakalang. Jenis ikan lain yang sudah berada di atas perahu akan disimpan ke dalam peti yang berisi es kecuali ikan layang akan di bawa langsung ke pasar lokal karena tangkapannya sangat banyak.

\section{Distribusi Iluminasi Cahaya Dalam Air}

Pola sebaran iluminasi cahaya dalam air dengan menggunakan lampu normal yang di ukur secara horizontal dan vertikal. (Gambar 4).
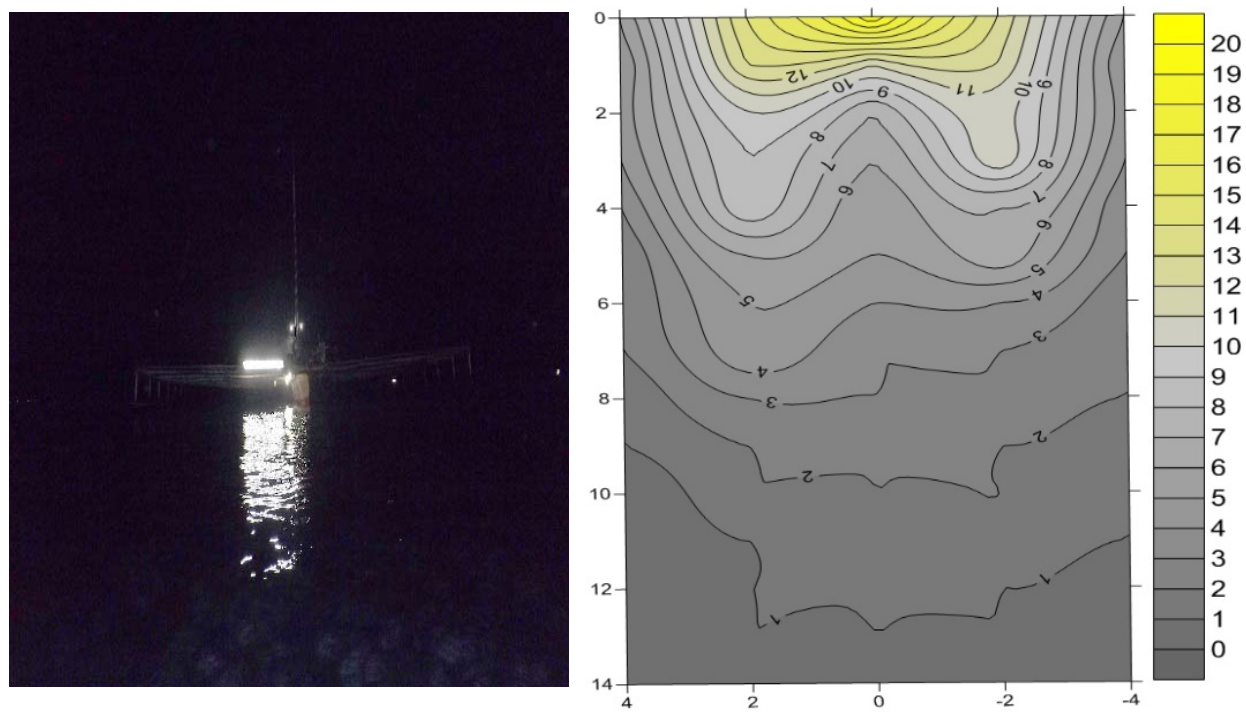

Gambar 4 Pola sebaran iluminasi cahaya lampu normal

Nilai iluminasi cahaya pada sisi sebelah kanan bagan perahu cahaya yang terbaca berada pada jarak $4 \mathrm{~m}$, dan sisi sebelah kiri bagan perahu cahaya yang terbaca berada pada jarak $2 \mathrm{~m}$. Nilai pengukuran secara horizontal intensitas cahaya sangat rendah karena lampu yang digunakan di atas bagan ditempatkan hanya di sisi sebelah kanan dan di tengah samping kanan bagan perahu. Pengukuran secara vertikal dengan tiap-tiap jarak pengukuran $1 \mathrm{~m}$ sampai pada kedalaman yang tidak terbaca oleh underwater lux meter. Cahaya underwater lux meter nilai yang paling tertinggi yaitu 20 lux dengan kedalaman $(0 \mathrm{~m})$ atau di permukaan bagan perahu, sedangkan yang paling terendah cahaya yang masuk secara vertikal pada kedalam 14 m. Menurut Anggawangsa et al. (2013) menyebutkan perbedaan iluminasi atraktor cahaya pada bagan apung berpengaruh terhadap komposisi hasil tangkapan. 
Pengoperasian bagan perahu menggunakan cahaya untuk menarik dan mengumpulkan ikan pada catchable area. Jumlah penggunaan lampu yang berada di atas bagan perahu 14 unit lampu philips, kapasitas dari masing-masing lampu 24 dan 32 watt. lampu yang dipasang terdapat di sisi kanan bagan dan sisi tengah bagan. Daya tembus dari cahaya lampu philips pada kedalaman 14 meter iluminasi cahaya dari permukaan secara vertikal mencapai 20 lux (0 meter), hal ini menunjukkan bahwa kapasitas lampu yang digunakan oleh nelayan Desa Bajo dengan jumlah terlalu sedikit, sehingga pada saat pengoperasian pada bulan terang kurang efektif. Menurut Puspito et al. (2012) menyebutkan iluminasi cahaya tertinggi terdapat di kedalaman 1 meter karena dekat dengan sumber cahaya. Hasil dari distribusi intensitas cahaya yang diukur melalui kombinasi antara lampu yang dipasang di atas bagan dan lampu dalam air.

\section{Pola sebaran intensitas cahaya lampu normal dan underwater light fishing}

Sebaran intensitas cahaya yang diukur berdasarkan kombinasi antara lampu normal dan underwater light fishing secara horizontal maupun vertikal (Gambar 5).

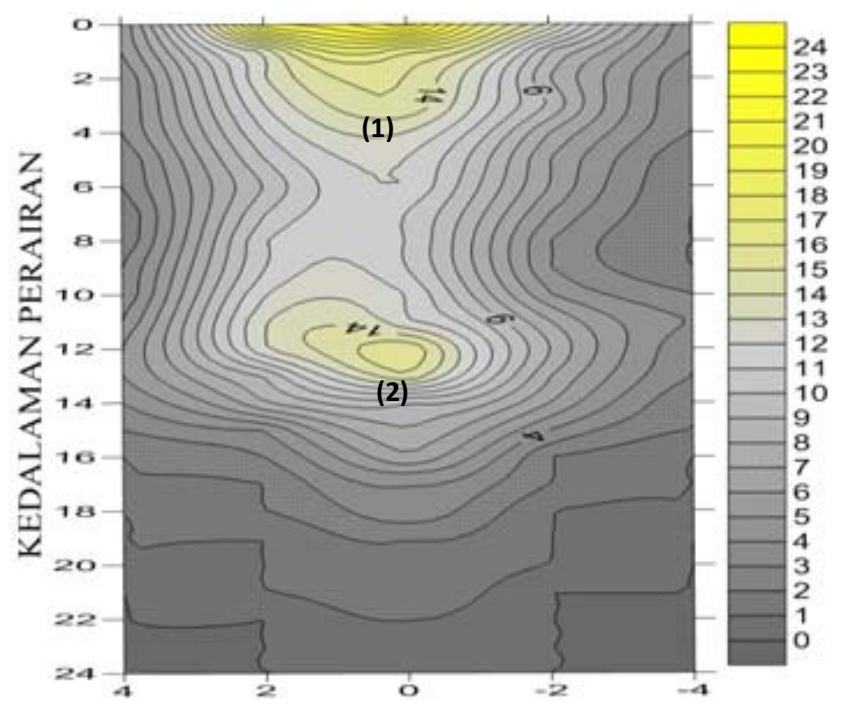

Gambar 5 Pola sebaran iluminasi cahaya (1) lampu normal (2)underwater light fishing

Pengukuran secara horizontal di sisi sebelah kanan, cahaya yang terbaca oleh underwater lux meter berada pada jarak $4 \mathrm{~m}$, sedangkan di sisi sebelah kiri cahaya yang terbaca pada jarak $2 \mathrm{~m}$. Nilai pengukuran iluminasi cahaya secara vertikal pada tiap-tiap pengukuran diawali dengan interval $1 \mathrm{~m}$ sampai pada kedalaman yang tidak terbaca oleh underwater lux meter. Nilai iluminasi cahaya secara vertikal yang diperlihatkan pola sebaran intensitas cahaya lampu normal dan underwater light fishing yang masuk ke dalam perairan berada pada kedalaman $24 \mathrm{~m}$. Nilai lux tertinggi 24 lux berada pada permukaan bagan (0 meter). Menurut Puspito et al (2017) bahwa pemusatan cahaya dengan intensitas tinggi akan memudahkan proses penangkapan.

Hasil nilai dari pengukuran kedua sebaran cahaya lebih jauh dibandingkan nilai lux sebaran cahaya pengukuran pertama. Penggunaan lampu harus berkapasitas besar sehingga pada saat bulan terang bisa melakukan pengoperasian bagan perahu. Pemilihan iluminasi terhadap setiap spesies di areal bagan rambo dimana ikan teri memilih zona iluminasi tinggi dan berada pada bagian permukaan air. Jenis-jenis ikan lainnya seperti ikan layang, kembung, tembang, japuh dan selar, memilih zona iluminasi rendah 1-5 lux, seperti yang dikemukanan oleh Fuad et al. (2016) Penggunaan lampu dalam air pada bagan tancap menghasilkan hasil tangkapan ikan yang lebih banyak dibandingkan dengan menggunakan lampu petromaks. Pengukuran iluminasi cahaya yang menggunakan lampu normal dan lampu dalam air, dapat membantu pengoperasian bagan perahu. 


\section{Hasil Tangkapan}

Hasil tangkapan total yang diperoleh selama penelitian, yang dilakukan satu bulan, baik bulan gelap maupun bulan terang oleh dua perlakuan yaitu perlakuan menggunakan lampu normal dan perlakuan lampu normal, fish finder dan underwater light fishing (Tabel 2).

Tabel 2 Hasil tangkapan selama penelitian

\begin{tabular}{lccc}
\hline \multicolumn{1}{c}{ Perlakuan } & \multicolumn{2}{c}{ Bulan } & \multirow{2}{*}{ Total/Kg } \\
\cline { 2 - 3 } & Gelap & Terang & 7.949 \\
\hline $\begin{array}{l}\text { Lampu Normal } \\
\text { Lampu normal, Fishfinder }\end{array}$ & 4.916 & 3.033 & 13.161 \\
dan Underwater light fishing & 9.801 & 3.360 & \\
\hline
\end{tabular}

Pengoperaisan terbagi atas 2 kali setting. Setting pertama sebelum tengah malam dimulai pada pukul 18.00-00.00 WIT sedangkan setting kedua setelah tengah malam dimulai pada pukul 00.0006.00 WIT dini hari. Tangkapan bagan tertinggi berada pada perlakuan kedua yaitu lampu normal, fish finder dan underwater light fishing. Hasil tangkapan pada perlakuan pertama lampu normal bulan gelap, yang paling tertinggi $4.916 \mathrm{~kg}$, sedangkan yang paling terendah berada pada bulan terang $3.033 \mathrm{~kg}$.

Perlakuan kedua lampu normal, fish finder dan underwater light fishing pada bulan gelap hasil tangkapan yang paling banyak tertangkap $9.801 \mathrm{~kg}$ sedangkan yang paling terendah berada pada bulan terang $3.360 \mathrm{~kg}$. Perlakuan lampu normal selama penelitian baik pada saat bulan gelap maupun bulan terang $7.949 \mathrm{~kg}$, sedangkan perlakuan kedua lampu normal, fish finder dan underwater light fishing pada bulan gelap maupun bulan terang $13.161 \mathrm{~kg}$. Rata-rata total hasil tangkapan yang di lakukan dengan dua perlakuan, menunjukkan bahwa perlakuan kedua lebih mendominasi selama penelitian. (Gambar 6)

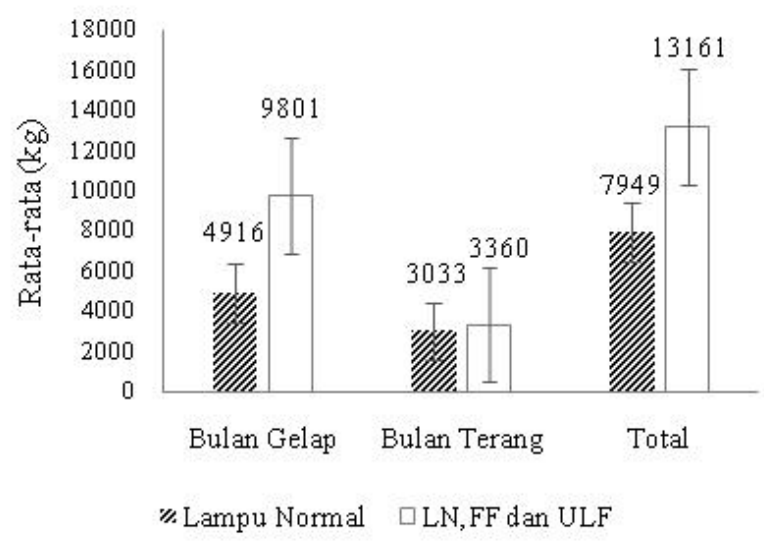

Gambar 6 Jumlah hasil tangkapan selama penelitian

Perlakuan berdasarkan dua fase bulan yang berbeda, pada saat bulan gelap di perlakuan lampu normal, jumlah tangkapan $4.916 \mathrm{~kg}$, sedangkan untuk perlakuan kedua lampu normal, fish finder dan underwater light fishing pada bulan gelap $801 \mathrm{~kg}$, kemudian pada bulan terang untuk perlakuan lampu normal $3.033 \mathrm{~kg}$, sedangkan untuk perlakuan kedua lampu normal, fish finder dan underwater light fishing pada bulan terang $3.360 \mathrm{~kg}$. Hasil tangkapan berdasarkan dua perlakuan dengan dua fase bulan yang berbeda yaitu perlakuan kedua lebih mendominasi yang terdapat pada bulan gelap, sedangkan yang paling terendah berada pada perlakuan pertama yang terdapat pada bulan terang. Hasil penelitian ini menunjukkan bahwa komposisi jenis hasil tangkapan lebih banyak pada waktu 
setelah tengah malam. Menurut Fauziyah et al. (2013) bahwa waktu penangkapan bagan tancap yang paling optimal adalah saat tengah malam, hal ini senada dengan penelitian Baskoro (1999) bahwa keragaman jenis ikan pada saat tengah malam lebih tinggi dibandingkan sebelum tengah malam dan pada saat setelah tengah malam keragaman jenis sedikit. Hasil tangkapan selama penelitian menunjukan bahwa total hasil tangkapan baik pada bulan gelap maupun terang, jenis ikan layang dan ikan teri lebih mendominasi berada pada perlakuan ke dua, sedangkan komposisi hasil tangkapan setelah tengah malam organisma lebih banyak dibandingkan sebelum tengah malam.

\section{Analisis ANOVA}

Analisis hasil tangkapan yang digunakan adalah rancangan faktorial hal ini dapat melihat pengaruh hasil tangkapan terhadap fase bulan, perlakuan maupun waktu penangkapan adapun hasil analisis ANOVA dapat di sajikan pada Tabel 3.

Tabel 3 Hasil Analisis ANOVA tangkapan

\begin{tabular}{lrccrc}
\hline Sumber keragaman & Jumlah kuadrat & $\begin{array}{c}\text { Derajat } \\
\text { bebas }\end{array}$ & Kuadrat tengah & Fhit & P-value \\
\hline Fase bulan & $2.887 .040,667$ & 1 & $2.887 .040,667$ & 33,96 & 0,00 \\
Waktu & $61.004,167$ & 1 & $61.004,167$ & 0,71 & 0,40 \\
Perlakuan & $491.920,667$ & 1 & $491.920,667$ & 5,78 & 0,02 \\
\hline
\end{tabular}

Berdasarkan (Tabel 3) di atas dapat diketahui bahwa fase bulan memberikan pengaruh nyata terhadap hasil tangkapan. Hal ini dapat dilihat dari nilai P-value yang lebih kecil dari nilai taraf nyata 0,05, maka perberadaan fase bulan bahwa perlakuan memberikan perbedaan terhadap hasil tangkapan yang diperoleh, apabila dilihat berdasarkan nilai rata-rata perlakuan penangkapan maka perlakuan yang menghasilkan jumlah tangkapan terbesar adalah pada perlakuan kedua yaitu lampu normal, fish finder dan underwater light fishing $13.161 \mathrm{~kg}$ dan hasil tangkapan paling rendah terjadi pada perlakuan pertama yaitu lampu normal $7.949 \mathrm{~kg}$.

Jumlah tangkapan terbaik berdasarkan dua fase bulan yang berbeda yang disajikan pada (Tabel 2) bahwa hasil tangkapan menunjukan bahwa bulan gelap mendominasi hasil tangkapan selama penelitian, hal ini didasari dengan uji ANOVA pada bulan gelap memberikan pengaruh nyata terhadap hasil tangkapan. Kedua perlakuan memiliki interaksi yang positif dimana kombinasi keduanya perlakuan memberikan pengaruh nyata terhadap hasil tangkapan. Fase bulan ini memberikan tangkapan terbaik pada bulan gelap karena ikan teradaptasi sempurna oleh cahaya lampu yang dipasang di atas bagan. Pada intensitas cahaya yang sama tetapi pada jarak yang berbeda akan memberikan hasil tangkapan yang berbeda pula. Menurut Notanubun dan Patty (2010) pada hasil penelitiannya bahwa hasil tertangkap bagan apung yang diperoleh selama penelitian umumnya jenis-jenis ikan pelagis kecil fototaksis positif yang tertarik pada cahaya.

Hasil dari uji ANOVA menunjukkan bahwa nilai hasil tangkapan berbeda nyata antara kedua lampu yang digunakan, dengan nilai $\mathrm{f}$ hitung $=5,787>\mathrm{f}$ tabel $=0,026$. Adapun hasil analisis berdasarkan fase bulan menunjukkan bahwa terdapat perbedaan nyata yang terlihat dari nilai $\mathrm{f}$ hitung $=33,963$ lebih besar daripada $\mathrm{f}$ tabel $=0,000$. Sedangkan waktu mempuyai nilai signifikan yang berbeda sebesar 0,718 dengan nilai $f$ tabel 0,407 .

\section{Perbandingan Bulan Gelap dan Bulan Terang}

Spesies yang tertangkap sebanyak enam jenis, antara lain Teri (Stolepharus sp), Pepetek (Leiognathus sp), Selar tetengkek(Megalaspis cordyla), Alu-alu (Sphyraena jello), Layang (Decapterus russelli) dan Cumi-cumi (Loligo sp)(Tabel 4). 
Tabel 4 Perbandingan hasil tangkapan berdasarkan bulan

\begin{tabular}{lrr}
\hline \multirow{2}{*}{ Jumlah Spesies } & \multicolumn{2}{c}{ Perbandingan Fase Bulan } \\
\cline { 2 - 3 } \cline { 2 - 3 } Teri & Gelap & Terang \\
Pepetek & 3.629 & 1.369 \\
Tetengkek & 539 & 205 \\
Alu-alu & 905 & 428 \\
Layang & 474 & 216 \\
Cumi-cumi & 8.310 & 3.573 \\
\hline
\end{tabular}

Hasil tangkapan yang diperoleh bahwa spesies ikan layang lebih mendominasi selama penelitian berdasarkan fase bulan yang berbeda, pada bulan gelap tangkapan ikan layang sebanyak $8.310 \mathrm{~kg}$, dan pada bulan terang $3.573 \mathrm{~kg}$, hal tersebut diduga karena ikan layang teradaptasi sempurna oleh cahaya.

Hasil tangkapan menurut spesies yang diperoleh selama penelitian dengan dua perlakuan, uji coba pertama dengan lampu normal dan uji coba kedua dengan lampu normal, fish finder dan underwater light fishing. Pada masing-masing perlakuan terbagi atas tiga trip pada saat bulan gelap dan bulan terang, dalam satu trip dilakukan dua kali setting, setting pertama sebelum tengah malam dan setting kedua setelah tengah malam. Spesies yang tertangkap terdiri atas 6 jenis spesies yaitu Teri (Stolepharus sp), Pepetek (Leiognathus sp), Selar tetengkek (Megalaspis cordyla), Alu-alu (Sphyraena jello), Layang (Decapterus russelli) dan Cumi-cumi (Loligo sp). Perbandingan hasil tangkapan berdasarkan dua fase bulan yang berbeda (Gambar 7).

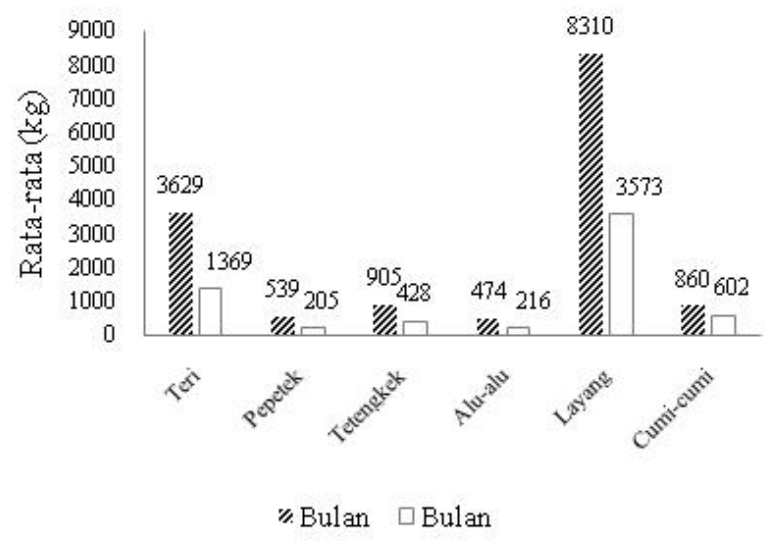

Gambar 7 Perbandingan jumlah hasil tangkapan berdasarkan bulan

Layang (Decapterus russelli) hasil tangkapan yang dominan tertangkap dari semua spesies yang ada. Pada saat bulan gelap hasil tangkapan dengan jumlah $8.310 \mathrm{~kg}$, dan pada bulan terang dengan jumlah tangkapan sebanyak $3.573 \mathrm{~kg}$. Spesies Cumi-cumi (Loligo sp) tangkapan pada saat bulan gelap yang diperoleh sebanyak $860 \mathrm{~kg}$, dan pada bulan terang tangkapan yang diperoleh $602 \mathrm{~kg}$. Hasil tangkapan layang selama penelitian pada bulan September-Oktober 2016 adalah musim penangkapan ikan layang di perairan Botang Loman, sesuai dengan data produksi hasil tangkapan Dinas Kelautan dan Perikanan Kabupaten Halmahera Selatan (DKP, 2016) terhitung mulai dari Bulan JanuariOktober 2016 mencapai 5.820,43 Ton, hal ini senada dengan penelitian Chodriyah dan Hariati (2010) bahwa musim penangkapan ikan layang didasarkan atas nilai indeks musim penangkapan ikan menunjukkan bahwa musim ikan layang terjadi sekitar pada bulan Mei sampai September dan November sampai Desember dimana nilai indeks musim penangkapannya berkisar di atas 100\%. 
Teri (Stolepharus sp) pada saat bulan gelap $3.629 \mathrm{~kg}$, dan pada bulan terang $1.369 \mathrm{~kg}$. Pepetek (Leiognathus sp) tangkapan pada bulan gelap $539 \mathrm{~kg}$, dan pada saat bulan terang $205 \mathrm{~kg}$. Selar tetengkek (Megalaspis cordyla) tangkapan bulan gelap $905 \mathrm{~kg}$, tangkapan bulan terang $428 \mathrm{~kg}$. Alualu (Sphyraena jello) tangkapan bulan gelap $474 \mathrm{~kg}$, tangkapan bulan terang $216 \mathrm{~kg}$, layang (Decapterus russelli) hasil tangkapan yang dominan tertangkap dari semua spesies yang ada. Pada saat bulan gelap $8.310 \mathrm{~kg}$, dan pada bulan terang $3.573 \mathrm{~kg}$. Cumi-cumi (Loligo sp) tangkapan bulan gelap $860 \mathrm{~kg}$, tangkapan pada bulan terang $602 \mathrm{~kg}$.

Teri (Stolephorus sp) tangkapan kedua selama penelitian baik pada saat bulan gelap maupun bulan terang. Ikan ini setiap kali melakukan penangkapan sering tertangkap oleh jaring bagan. Menurut Thenu et al. (2013) bahwa dampaknya, keberadaan kelompok teri yang besar akan mengundang organisma predator, seperti layur dan cumi-cumi, untuk datang dan memangsanya. Spesies teri yang mendominasi tangkapan kedua selain layang dengan menggunakan dua perlakuan bahwa perlakuan kedua lampu normal, fish finder dan underwater light fishing yang mendominasi, hal ini karena pada saat gerombolan ikan berada lebih dalam maka dapat di ujicoba dengan alat bantu lampu dalam air sehingga bisa mengumpulkan pada areal bagan.

Selar tetengkek (Megalaspis cordyla) menjadi tangkapan ketiga selama penelitian pada saat bulan gelap. Spesies ini juga lebih menyenangi terhadap cahaya yang dipasang pada bagan perahu. Hasil tangkapan berdasarkan dua fase bulan yang berbeda terlihat bahwa semua spesies yang tertangkap rata-rata pada saat bulan gelap.

Cumi-cumi (Loligo sp) yang sering tertangkap pada saat bulan gelap maupun bulan terang. Tetapi yang paling banyak tertangkap pada saat bulan gelap dan setiap pengoperasian selalu tertangkap dengan jaring bagan, hal ini juga lebih banyak tertangkap pada perlakuan kedua menggunakan lampu normal, fish finder dan underwater light fishing karena cumi-cumi lebih senang terhadap cahaya. Penelitian yang dilakukan oleh Taufiq (2013) bahwa makanannya berupa ikan dan udang. Oleh karena itu, cumi-cumi tertangkap bagan disebabkan oleh keberadaan makanannya yang bersifat fototaksis positif di bawah bagan.

Pepetek (Leiognathus sp) yang tertangkap sering tertangkap bersamaan dengan ikan teri. Ikan jenis ini sering tertangkap pada saat bulan gelap maupun bulan gelap dan disenangi terhadap cahaya. Menurut Utami (2009) pada hasil penelitiannya bahwa tingkah laku pepetek sesaat setelah lampu dinyalakan adalah perlahan-lahan ikan tersebut mendekati cahaya dan berputar-putar pada bagian cahaya yang masih remang-remang di air. Gerombolan ikan tersebut kemudian menuju ke tempat yang lebih terang yaitu daerah yang langsung diterangi oleh cahaya.

Tangkapan yang terendah selama penelitian adalah alu-alu (Sphyraena jello) selama penelitian pada saat bulan gelap mengalami peningkatan. Sedangkan pada saat bulan terang mengalami penurunan. Jenis spesies ini disebabkan karena mencari makan dengan cara memangsa atau memburu ikan-ikan kecil sehingga tertangkap oleh jaring, seperti hasil penelitian Sulaiman et al. (2006) pada hasil penelitiannya bahwa umumnya ikan predator diduga karena mencari makan seperti ikan barakuda, cendro, dan layur. Target utama penangkapan adalah ikan teri, namun pada bulan September dan Oktober hasil tangkapan ikan layang jauh lebih banyak dibandingkan ikan teri.

\section{Uji Coba Perlakuan}

Penelitian yang berlangsung dilakukan dengan dua perlakuan. Perlakuan pertama lampu normal dan perlakuan kedua lampu normal, fish finder dan underwater light fishing (Tabel 5). 
Tabel 5 Hasil ujicoba Perlakuan

\begin{tabular}{lcc}
\hline & \multicolumn{2}{c}{ Ujicoba Perlakuan } \\
\cline { 2 - 3 } & Spesies & $\begin{array}{c}\text { Lampu normal, Fish finder dan } \\
\text { Underwater light fishing }\end{array}$ \\
\cline { 2 - 3 } Teri & 1.537 & 3.461 \\
Pepetek & 462 & 282 \\
Tetengkek & 388 & 945 \\
Alu-alu & 222 & 487 \\
Layang & 4.831 & 7.052 \\
Cumi-cumi & 528 & 934 \\
\hline
\end{tabular}

Penelitian yang berlangsung dilakukan dengan dua perlakuan, yang pertama perlakuan lampu normal yang dimilliki oleh nelayan Desa Bajo, yang kedua perlakuan dengan lampu normal dan underwater light fishing, dari kedua perlakuan ini, hasil tangkapan yang banyak berada pada perlakuan kedua, karena pada saat ikan berada pada posisi yang lebih dalam posisi ikan tidak terjangkau oleh cahaya yang dipasang di atas bagan maka underwater light fishing yang membantu untuk diturunkan ke dalam perairan, untuk ditarik ke atas hingga gerombolan ikan berada pada posisi yang terjangkau oleh intensitas cahaya yang dipasang di atas bagan perahu (Gambar 8).

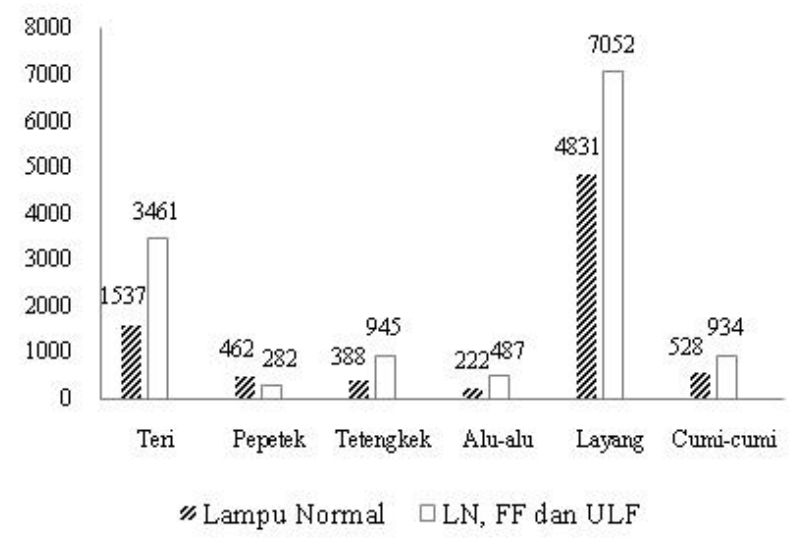

Gambar 8 Uji coba perlakuan

Hasil tangkapan yang diperoleh selama penelitian didominasi oleh layang (Decapterus ruselli), pada perlakuan kedua lampu normal, fish finder dan underwater light fishing. Menurut Sudirman et al. (2013) dalam hasil penelitian menunjukan bahwa lampu neon memberikan hasil tangkapan yang lebih baik dibandingkan dengan jenis lampu merkuri dan pijar. Sedangkan tangkapan yang paling rendah adalah alu-alu (Sphyraena jello), seperti yang disajikan pada (Gambar 8) bahwa tangkapan teri (Stolepharus sp) pada perlakuan pertama $1.537 \mathrm{~kg}$, sedangkan perlakuan kedua $3.461 \mathrm{~kg}$. Tangkapan pepetek (Leiognathus sp) pada perlakuan pertama $462 \mathrm{~kg}$, sedangkan perlakuan kedua lebih rendah $282 \mathrm{~kg}$. Tangkapan tetengkek (Megalaspis cordyla) pada perlakuan pertama $388 \mathrm{~kg}$, sedangkan perlakuan kedua $945 \mathrm{~kg}$. Tangkapan alu-alu (Sphyraena jello) pada perlakuan pertama $222 \mathrm{~kg}$, sedangkan perlakuan kedua $487 \mathrm{~kg}$. Tangkapan layang (Decapterus russelli) pada perlakuan pertama 4 $831 \mathrm{~kg}$, sedangkan yang paling tertinggi berada pada perlakuan kedua $7.052 \mathrm{~kg}$. Tangkapan cumicumi (Loligo sp), perlakuan lampu normal $528 \mathrm{~kg}$, sedangkan yang paling tertinggi berada pada perlakuan kedua $934 \mathrm{~kg}$.

Kelimpahan ikan tertinggi terdapat pada perlakuan kedua menggunakan lampu normal fish finder dan underwater light fishing. Hasil tangkapan berdasarkan dua perlakuan bahwa tangkapan 
yang terbaik berada pada perlakuan kedua, tetapi ada spesies yang tertangkap pada perlakuan pertama yang menggunakan lampu normal oleh nelayan Desa Bajo. Ikan-ikan yang tertangkap oleh lampu normal ini kemungkinan ikan yang senang dengan cahaya yang redup sehingga pada saat melakukan penangkapan banyak ikan yang tertangkap pada perlakuan pertama yaitu hanya lampu normal yang digunakan oleh nelayan setempat.

\section{KESIMPULAN DAN SARAN}

\section{Kesimpulan}

Berdasarkan hasil penelitian dari analisis penggunaan alat di perairan Botang Loman Halmahera Selatan maka dapat disimpulkan :

1. Hasil tangkapan total oleh enam jenis ikan yang dominan tertangkap adalah, spesies layang (Decapterus russelli) mendominasi selama penelitian.

2. Hasil tangkapan oleh enam jenis ikan yang dominan tertangkap adalah, spesies layang (Decapterus russelli) mendominasi selama penelitian. Fase bulan yang terbaik adalah pada saat bulan gelap. Hasil tangkapan pada perlakuan kedua menggunakan lampu normal, fish finder dan underwater light fishing mendominasi selama penelitian.

Saran

Saran yang dapat diberikan dari hasil penelitian ini adalah untuk mengoptimalkan perikanan bagan perahu maka perlu melakukan kombinasi dengan lampu normal, fish finder dan underwater light fishing waktu penangkapan pada saat bulan gelap dan bulan terang. Agar perikanan bagan di Desa Bajo Perairan Botang Loman Kabupaten Halmahera Selatan lebih efektif dan efisien.

\section{DAFTAR PUSTAKA}

[DKP] Dinas Kelautan danPerikanan. 2016. Data Produksi Hasil Tangkapan Halmahera Selatan.

Anggawangsa RF, Hargiyanto IT, Wibowo B. 2013. Pengaruh Iluminasi Atraktor Cahaya Terhadap Hasil Tangkapan Ikan Pada Bagan Apung. Jurnal Perikanan Indonesia 19(2):105-111.

Ayodhyoa AU. 1981. Teknik Penangkapan Ikan. Bogor (ID): Yayasan Dewi Sri.

Baskoro MS. 1999. Capture Process of The Floated Bamboo-Platform Liftnet With Light Attraction (Bagan). Graduate School of Fisheries, Tokyo University of Fisheries. Doctoral Course of Marine Sciences and Technology. P 149.

Chodriyah U, Hartati T. 2010. Musim Penangkapan Pelagis Kecil Di Laut Jawa. Jurnal Perikanan. 16(3):217-223.

Fauziyah, Supriyadi F, Saleh K, Hardi. 2013. Perbedaan Waktu Hauling Bagan Tancap terhadap Hasil Tangkapan di Perairan Sungsang, Sumatera Selatan. Jurnal Lahan Suboptimal. 2(1):50-57.

Fuad, Sukandar, Jauhari A. 2016. Pengembangan Lampu Bawah Air Sebagai Alat Bantu pada Bagan Tancap di Desa Tambak Kelok Kecamatan Lekok Pasuruan. Jurnal Kelautan. 9(1):7-11.

Lee JW. 2010. Pengaruh Periode Hari Bulan terhadap Hasil Tangkapan Pendapatan Nelayan Bagan Tancap di Kabupaten Serang. [tesis]. Bogor (ID) Institut Pertanian Bogor.

Martasuganda S. 2014. Bahan Kuliah Jaring Angkat (Lift Net Fishery) Bagan. Teknologi Perikanan Laut, Fakultas Perikanan dan Ilmu Kelautan; Institut Pertanian Bogor. 
Notanubun J, Patty W. 2010. Perbedaan Penggunaan Intensitas Cahaya Lampu Terhadap Hasil Tangkapan Bagan Apung di Perairan Selat Rosenberg Kabupaten Maluku Tenggara Kepulauan Kei. Jurnal Perikanan dan Kelautan Tropis 6(3):134-140.

Puspito G, Ahmad S, Sururi M. 2017. Selection of Lamp Reflector Construction and Fishing Time of Lift Net. Egyptian Journal Of Aquatic Research. (30):30-30.

Puspito G. 2012. Pengaruh Pemusatan Cahaya Terhadap Efektivitas Bagan. Jurnal Saintek Perikanan 7(2):5-9.

Safrudin. 2013. Distribusi Ikan Layang (Decapterus sp) Hubungannya dengan Kondisi Oseanografi di Perairan Kabupaten Pangkep, Sulawesi Selatan. Jurnal Ilmu Kelautan Dan Perikanan. (23):150156

Sudirman, Baskoro MS, Purbayanto A, Monintja DRM, Jufri M, Arimoto T. 2003. Adaptasi Retina Mata Ikan Layang (Decapterus ruselli) terhadap Cahaya dalam Proses Penangkapan pada Bagan Rambo di Selat Makassar. Jurnal Ilmu-Ilmu Perairan dan Perikanan Indonesia. 10(2):85-92

Sudirman, Najamuddin, Palo M. 2013. Efektivitas Penggunaan Berbagai Jenis Lampu Listrik untuk Menarik Perhatian Ikan Pelagis Kecil pada Bagan Tancap. Fakultas Ilmu Kelautan Dan Perikanan Universitas Hasanuddin, Makassar

Sulaiman M, Jaya I, Baskoro MS. 2006. Studi Tingkah Laku Ikan pada Proses Penangkapan dengan Alat Bantu Cahaya: Suatu Pendekatan Akustik. Jurnal Ilmu Kelautan. 11(1):31-36

Taufiq I. 2013. Kebiasaan Makan dan Komposisi Makanan Tiga Species Cumi (Loligo edulis, Sepioteuthis lessoniana dan Sepia officinalis) Hasil Tangkapan Nelayan dari Perairan Pantai Utara Provinsi Aceh. Depik Jurnal Ilmu-ilmu Perairan, Pesisir, dan Perikanan 2(2):97-103

Thenu IM, Puspito G, Martasuganda S. 2013. Penggunaan Light Emitting Diode pada Lampu Celup Bagan. Jurnal Marine Fisheries. 4(2):141-151

Utami E. 2009. Analisis Respon Tingkah Laku Ikan Pepetek terhadap Intensitas Cahaya Berwarna. Jurnal Sumberdaya Perairan 3(2):1-4 